\title{
In Vivo Thyroid Monitoring for Iodine-131 in the Environment*
}

\author{
PHILLIP PLATO and A. P. JACOBSON \\ Department of Environmental and Industrial Health, School of Public Health, The \\ University of Michigan, Ann Arbor, MI, U.S.A. \\ and \\ STEVEN HOMANN \\ Lawrence Livermore Laboratory, Livermore, CA, U.S.A.
}

(Received 1 January 1976)

\begin{abstract}
Monitoring of air and milk samples is done routinely around nuclear facilities that release iodine-131 to the environment. Results from these measurements are used to calculate dose rates to the thyroids of people who live near such facilities. These calculated dose rates have large uncertainty factors associated with them due to the complexity of predicting the movement of iodine-131 through the environment. This paper describes an effort to monitor iodine-131 directly in the thyroids of individuals living in the environment. A NaI(Tl)-detector system was assembled in the back of a truck for rapid and convenient measurements of members of the general public. The monitoring system has a minimum detectable activity for thyroid-bound iodine- 131 of approx. $35 \mathrm{pCi}$ which is sensitive enough to satisfy all legal requirements for environmental monitoring in the U.S.A. except for the child who receives iodine-131 continuously from a nuclear-power plant. Thyroid doses are calculated with more certainty from in vivo measurements than from measurements made on environmental and effluent samples.
\end{abstract}

\section{INTRODUCTION}

Monitoring of iodine-131 released to the environment generally involves air sampling and, when feasible, milk sampling. The primary concern with the release of iodine-131 is the potential deposition of this radionuclide in the human thyroid. If iodine-131 is delivered to the thyroid continuously, the dose rate to the thyroid is calculated by:

$$
R=\frac{18.7 E q_{c}}{m},
$$

where: $R=$ dose rate to the thyroid $(\mathrm{mrad} / \mathrm{yr})$

$q_{r}=$ continuous thyroid burden $(\mathrm{pCi})$

$E=$ effective energy per disintegration $(\mathrm{MeV} / \mathrm{dis})$

$m=$ mass of the thyroid (g).

* This work was sponsored by a research grant from Consumers Power Company, Jackson, MI, U.S.A.
If iodine-131 is delivered to the thyroid in a single, short-term exposure, the activity in the thyroid will decrease exponentially. The total dose received from a single exposure is calculated by:

$$
D=\frac{18.7 E q_{0}}{m \lambda_{e}}\left(1-e^{-\lambda_{e^{\prime}}}\right),
$$

where: $\quad D=$ dose to the thyroid (mrad)

$q_{0}=$ initial thyroid burden (pCi)

$t=$ time since the initial thyroid burden was received (yr)

$\lambda_{e}=$ effective decay constant $=33.3 \mathrm{yr}^{-1}$ based on an effective half life of 7.6 days $^{(1)}$

$E$ and $m$ are defined previously.

Table 1 shows the continuaus and single thyroid burdens of iodine-131 that will deliver the maximum permissible dose rate to the thyroid for occupational workers and members of the general public. 
TABI: 1. Retationship between dose rate to the thyroid and the associated activity of thyroid-bound iodine-131

\begin{tabular}{|c|c|c|c|c|c|c|c|}
\hline \multirow[b]{2}{*}{ Type of person } & \multirow[b]{2}{*}{$\begin{array}{l}\text { Source of } \\
\text { lodine- } 131\end{array}$} & \multirow[b]{2}{*}{$\begin{array}{l}\text { Mass of } \\
\text { thyroid } \\
(\mathrm{g})^{*}\end{array}$} & \multirow[b]{2}{*}{$\begin{array}{l}\text { Effective } \\
\text { energy } \\
\left(\frac{\mathrm{MeV}}{\text { dis }}\right)^{\dagger}\end{array}$} & \multicolumn{2}{|c|}{$\begin{array}{l}\text { Maximum } \\
\text { permissible } \\
\text { dose rate }\end{array}$} & \multicolumn{2}{|c|}{$\begin{array}{l}\text { Thyroid burden to give } \\
\text { max. per. dose yr }\end{array}$} \\
\hline & & & & $\left(\frac{m r a d}{y r}\right)$ & $\begin{array}{l}\text { Legal } \\
\text { reference§ }\end{array}$ & $\begin{array}{c}\text { Continuous } \\
\text { burden } \\
\text { (pCi) }\end{array}$ & $\begin{array}{c}\text { Single } \\
\text { burden } \\
\text { (pCi) }\end{array}$ \\
\hline Occupational worker & Occupational & 16 & 0.23 & 12.000 & 10 CFR 20 & $44,600 \|$ & $372,6(\mathrm{~K})$ \\
\hline $\begin{array}{l}\text { General public-adult } \\
\text { inaximum exposuri }\end{array}$ & $\begin{array}{l}\text { All but } \\
\text { nuclear power }\end{array}$ & 16 & 0.23 & 500 & 10 CFR 20 & 1,860 & 61,900 \\
\hline $\begin{array}{l}\text { Gencral public-adult } \\
\text { average exposure }\end{array}$ & $\begin{array}{l}\text { Ail but } \\
\text { nuclear power }\end{array}$ & 16 & 0.23 & 170 & 10 CFR 20 & 635 & 21,100 \\
\hline Genera? public-child & $\begin{array}{l}\text { All but } \\
\text { nuclear power }\end{array}$ & $2 \ddagger$ & $0.21 \%$ & 170 & 10 CFR 20 & 87 & 2.880 \\
\hline General public--adult & Nuclear power & 16 & 0.23 & 15 & $\begin{array}{l}10 \text { CFR } 50 \\
\text { Appendix I }\end{array}$ & 56 & 1,860 \\
\hline Genemal public--child & Nuclear power & $2 \ddagger$ & $0.21 \neq$ & 15 & $\begin{array}{l}10 \text { CFR } 50 \\
\text { Appendix } 1\end{array}$ & 8 & 254 \\
\hline
\end{tabular}

* Ref. 2 for adults.

+ Kef. 3.

+ Appendix I-10 CFR 50 assumes the child has a 2-g thyroid. Due to the samaller dimensions of a 2-g thyroid the effective absorbed energy is less by 0.02 . This decrease is primarily due to the decrease in the gamna-ray dose component, as less thyroid tissue is traversed by the iodine- 131 gamma rays.

$\$$ I.cgal reterences are Title 10 of the U.S.A. Code of Federal Regulations, Parts 20 and 50. Dose equivalent values are given in these references in units of $\mathrm{mrem} / \mathrm{yr}$ with an assumed quality factor of unity.

if Since 10 (FR 20 does not specify a maximum allowable dose equivalent for the thyroid, calculated thyroid burdens ar: hased on the whole-body limit of 3,000 mrem per quarter for occupational workers.

Sources of iodine-131 include fallout from atmospheric nuclear-weapons tests and relexases from nuclear facilities such as nuclearpower plants, hositals and laboratories. Figure 1 shows the two major pathways, inhalation of air and ingestion of milk, through which iodine -131 can be transmitted from a typical source to the thyroid of an individual. Also shown in Fig. 1 are the four locations along the pathways where measurements of iodine131 ean be made and used to calculate thyroid doses. Transfer coefficients and an estimate of the uncertainty factors associated with each coefficient are shown along the air and milk pathways.

When measurements for iodine-131 have been made at the source or in the environment in samples of air or milk, further calculations and assumptions must be made before an estimation of a corresponding dose rate to a thyroid can be reported. Because of the relatively large uncertainty factor associated with each transfer coefficient in the air and milk pathways shown in Fig. 1, a large total uncertainty exists in the final estimation of iodine131 that reaches the general public. For example, if iodine-131 is detected in a milk sample, the uncertainty associated with the calculated dose rate to an individual's thyroid is determined by progagating the uncertainty factors shown in Fig. 1 along the ingestion pathway from MILK to THYROID; $\sqrt{2^{2}+2^{2}+1.5^{2}+1.5^{2}}=3.5$. $^{*}$ Thus, the actual dose rate to the thyroid could be as much as 3.5 times larger than the calculated dose rate or as little as one-third of the calculated value. Similarly, if iodine-131 is detected in an air

* Several statistical methods exist for propagating uncertainty factors. The authors believe, for the pathways shown in Fig. 1, that the method of quadrature produces the most realistic propagated uncertainties. 


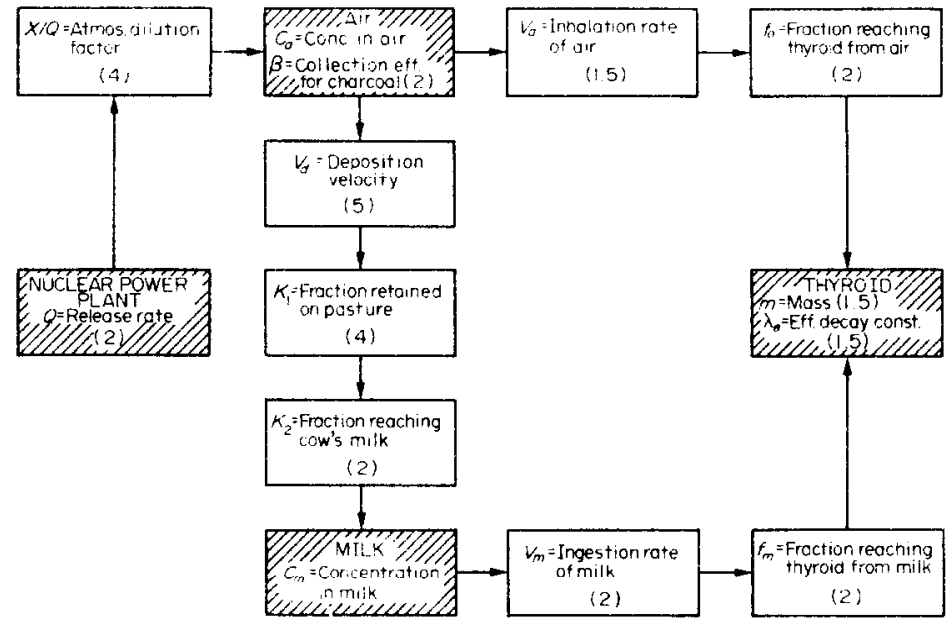

Fig. 1. Air and milk routes from a typical source of iodine-131 (nuclear-power plant) to a typical thyroid gland. Estimated uncertainty factors are shown in parenthesis for each transfer coefficient. For example, if a transfer coefficient has a mean value of $\Gamma$ with an uncertainty factor of $\gamma$, then actual values for the transfer coefficient are observed to range from $\gamma \Gamma$ to $\Gamma / \gamma$. Although specific values for these uncertainty factors are difficult to find in the literature, the authors believe the values shown are realistic. Shaded boxes indicate where direct measurements for iodine-131 can be made.

sample, the uncertainty factor associated with a calculated dose rate to an individual's thyroid is about 3.8 for the air-thyroid pathway and about 7.8 for the air-milk-thyroid pathway.

Direct measurements for iodine-131 can be made where gaseous wastes are discharged from a source to the environment as indicated in Fig. 1. These measurements, when multiplied by the atmospheric dilution factor, are used to calculate air concentrations of iodine131. The calculated air concentrations are used to calculate thyroid doses from inhalation of air and ingestion of milk. These calculated thyroid doses have the same uncertainties associated with the calculated doses based on direct measurements of air and milk with additional uncertainties from the release rate and the atmospheric dilution factor. The total uncertainty associated with a calculated thyroid dose based on a measurement of iodine-131 at a source is about 5.6 for the air-inhalation route and about 8.8 for the milk-ingestion route.

Much of the uncertainty associated with a calculated dose to a thyroid based on air, milk and effluent measurements can be eliminated by direct, in vivo monitoring of a thyroid. The objective of our work was to determine the feasibility and sensitivity of in vivo monitoring of the thyroid for iodine-131 at or below the limit set in Appendix I to 10 CFR Part 50. This is the most stringent legal limit set in the United States and probably in the world. A detailed description of the equipment and procedures used is available. ${ }^{(4)}$

\section{PROCEDURE}

\section{Instrumentation}

Measurement of iodine-131 activity within a thyroid is made with a pair of $7.62-\mathrm{cm}$-dia. by $4.45-\mathrm{cm}$-thick $\mathrm{NaI}(\mathrm{Tl})$ crystals positioned above the neck between the clavicle and the thyroid cartilage (Adam's apple). The detectors are aligned as shown in Fig. 2.

Each detector is sheathed in a $0.64-\mathrm{cm}$ thick lead cylinder, which typically decreases the background count rate in the primary iodine131 photopeak region $(0.364 \mathrm{MeV})$ to $50 \%$ of the unshielded count rate. Additional shadow shielding is effected by the placement of standard lead bricks under the detectors in the plane of the mounting baseplate. The detectors and lead housing are mounted in 


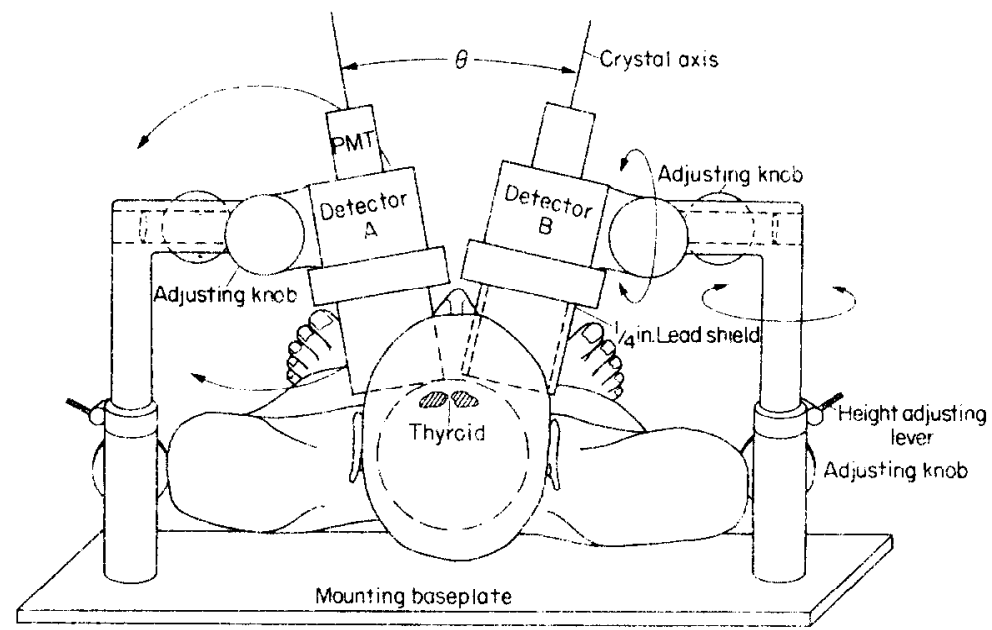

FIG. 2. Detector mounting for the mobile thyroid-monitoring system.

aluminum collars which are connected to the steel elbows shown in Fig. 2. The lead bricks are not shown.

Each detector is connected to a separate preamplifier/amplifier/discriminator

(PAD) module and then connected, in parallel, to a 256-channel pluse-height analyzer. This procedure allows separate PAD adjustments to compensate for individual gain shifts in each detector. The output of the combined detectors is monitored on an oscilloscope throughout the entire counting procedure. A Teletype is used to produce a permanent copy of each gamma-ray spectrum.

The electronic components and lead shielding weigh approximately $700 \mathrm{~kg}$. The equipment is easily carried and used in the back of a medium-size panel truck. This permits in vivo thyroid measurements to be made conveniently at the homes of members of the general public as part of routine environmental surveillance programs.

The total cost for the mobile thyroid monitoring system is approx. $\$ 7,000$.

\section{Calibration}

The average adult thyroid is assumed to have a height of $5 \mathrm{~cm}$, a breadth of $6 \mathrm{~cm}$, a thickness (each lobe) of $1.5 \mathrm{~cm}$, and a mass of $16 \mathrm{~g} .{ }^{(5)}$ The depth (center of one lobe to the surface of the skin) is assumed to be $2.3 \mathrm{~cm}$. ${ }^{(6)}$ A neck phantom was constructed to approximate this geometry. The phantom consisted of a polyethylene cylinder filled with water to approximate neck tissue. Two 5-ml glass ampoules, each containing a calibrated activity of iodine-131, were used to simulate the two lobes of a thyroid. A second neck phantom, with dimensions about two-thirds those of the first, was constructed to approximate the geometry of a child's neck. The depth of the thyroid in a child's neck is assumed to be $1.6 \mathrm{~cm} .{ }^{(6)}$ Counting efficiencies were measured with the adult and child phantoms for various detector positions and mock-thyroid depths. Figure 3 shows the effect of thyroid depth, measured from the center of one ampoule to the outside surface of the neck phantom, on the counting efficiency for both an adult and a

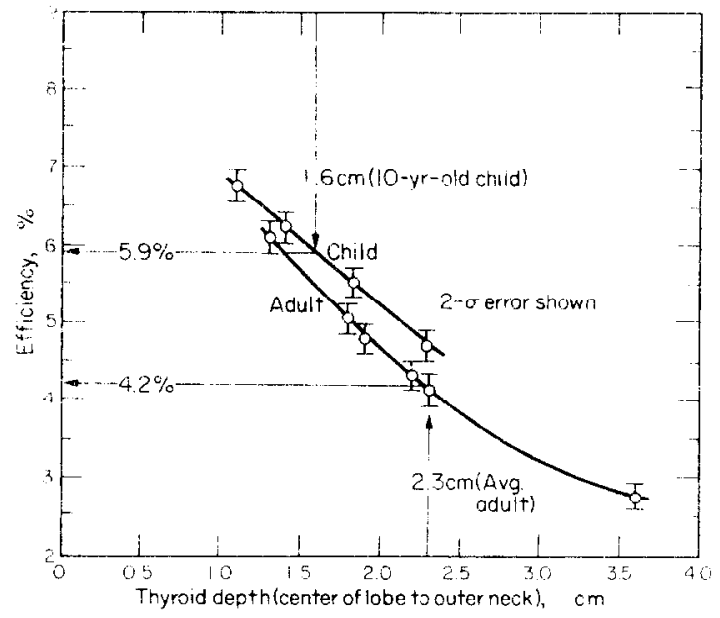

FIG. 3. Iodine-131 counting efficiency as a function of thyroid depth. 


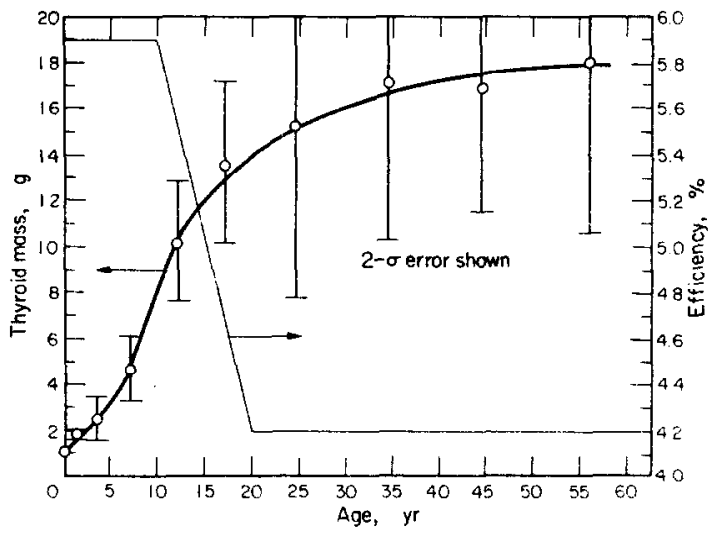

FIG. 4. Thyroid mass ${ }^{(7)}$ and iodine-131 counting efficiency as a function of age.

child. For a thyroid depth of $2.3 \mathrm{~cm}$ for the average adult, the counting efficiency was found to be $4.2 \%$. For a thyroid depth of $1.6 \mathrm{~cm}$ for the average $10-y r-o l d$ child, the counting efficiency was found to be $5.9 \%$.

The error bars shown in Fig. 3 represent the combination of the counting error (small due to the relatively high activity of the mock thyroid) and the error associated with the positioning of the detectors. The positioning error was determined by repetitive positioning of the detectors for the same geometry and by incorporating the resulting error into the variance of the observed count rate.

An age-dependent parameter required to calculate a thyroid dose based on a measured activity of iodine-131 in the thyroid is the mass of the organ. Data are available that show the increase in thyroid mass as a function of age. ${ }^{(7)}$ Figure 4 shows the relationship of both the mass of the thyroid and the counting efficiency to the age of a standard person. It is assumed that the counting efficiency varies linearly from $5.9 \%$ for a 10 -yr-old child to $4.2 \%$ for a 20 -yr-old adult.

\section{Sensitivity}

The analysis of each gamma-ray spectrum utilizes the 5 channels centered about the 0.364-MeV photopeak (channels 34-38, corresponding to $0.34-0.38 \mathrm{MeV}$ ). The time required to analyze each gamma-ray spectrum by the Compton continuum subtraction method is approximately 5 minutes. Thus, the measured iodine-131 thyroid burden can be reported to each person counted before he leaves the truck.

The minimum detectable activity (MDA) depends on the thyroid counting time, the background counting time, the background count rate, the Compton count rate, the counting efficiency, and the confidence level desired. The MDA, in units of $\mathrm{pCi}$, is calculated from:

$$
\mathrm{MDA}=\frac{\tau \sqrt{r / t_{s}+b / t_{b}+c / t_{s}}}{e 2.22},
$$

where $\tau=$ relative error $(\tau=1.96$ at the $95 \%$ confidence level)

$r=$ minimum detectable count rate of iodine-131 plus contributing count rates from background and the Compton continuum from iodine-131 (cpm)

$b=$ background count rate $(\mathrm{cpm})$

$c=$ Compton count rate from iodine-131 with background subtracted (cpm)

$t_{s}=$ thyroid counting time (min)

$t_{b}=$ background counting time (min)

$e=$ counting efficiency

$2.22=$ conversion factor $(\mathrm{dpm} / \mathrm{pCi})$.

Figure 5 shows a graph of MDA as a function of thyroid counting time for the measurement parameters specified. As can be seen in

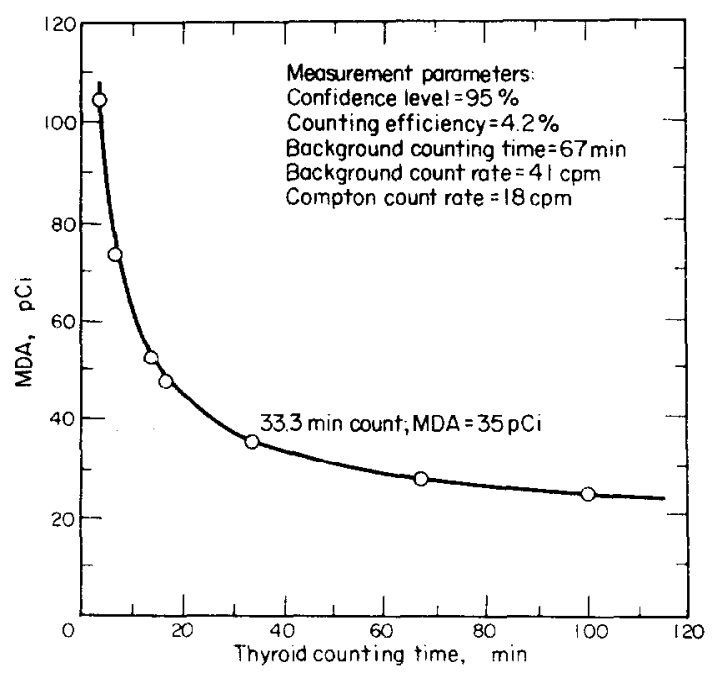

FIG. 5. Minimum detectable activity as a function of thyroid counting time. 
Fig. 5, a point of diminishing returns is reached in the vicinity of a 30-min counting time. For environmental monitoring of thyroids of members of the general public, a $33.3-\mathrm{min}(2000-\mathrm{sec})$ counting time is used since it is a reasonable length of time for the person being counted to endure, and the corresponding MDA of approx. $35 \mathrm{pCi}$ is acceptable. It would be preferable if the MDA were $1 / 4$ of this activity since the continuous thyroid burden which would deliver a dose of $15 \mathrm{mrad}$ to a child's thyroid in one year is $8 \mathrm{pCi}$ as shown in Table 1. However, reference to Fig. 5 shows this to be an unrealistic, perhaps impossible, achievement with the present thyroidmonitoring system due to the long counting time required.

\section{Uncertainty of calculated dose}

If iodine-131 is detected in an individual's thyroid from an in vivo measurement, an estimate must be made of the uncertainty associated with the corresponding calculated dose to the thyroid. If a continuous thyroid burden is observed after several in vivo measurements, the dose rate to the thyroid is calculated from equation (1). The mass, $m$, has an estimated uncertainty factor of 1.5 from Fig. 1. The measured thyroid activity, $q_{c}$, has an uncertainty from the count rate measured and from the counting efficiency, $e$, used in equation (3). Since the exact depth of the thyroid is not known for a given individual, variations from the average depths shown in Fig. 3 will cause variations in the counting efficiency. The total uncertainty factor associated with $q_{c}$ is estimated to be 1.5 . Thus, the propagated uncertainty factor associated with the calculated dose rate, $R$ in equation (1), is about 2.1 .

If iodine-131 is delivered to the thyroid in a single, short-term exposure, the total dose to the thyroid is calculated from equation (2). The thyroid mass, $m$, and the measured activity, $q_{0}$, each has an uncertainty factor of 1.5 . The effective decay constant, $\lambda_{e}$, also has an uncertainty factor of 1.5 from Fig. 1. If only a single in vivo measurement is made, the propagated uncertainty factor associated with the calculated total dose, $D$ in equation (2), is about 2.6. If several in vivo measurements are made following a single, short-term exposure to iodine-131, the actual value of $\lambda_{e}$ for the individual being studied can be determined with little uncertainty. Thus, the propagated uncertainty factor associated with the calculated total dose is about 2.1 .

\section{EXPERIMENTAL RESULTS}

As a pilot effort to determine the acceptability of the mobile thyroid-monitoring system by members of the general public, a dairy farm family living near a nuclear-power plant was counted during the summer of 1974 . The results, given in Table 2 , show no detectable iodine-131 in the thyroid of any member of the family. The family was enthusiastic about being counted.

The mobile thyroid-monitoring system measures iodine-131 activity, in units of picocuries, present in the thyroid. To convert a measured activity to a dose rate (e.g. $\mathrm{mrad} / \mathrm{yr}$ ), requires knowledge of the history of the iodine-131 in the thyroid. For example, the husband was found to have $<40 \mathrm{pCi}$ of iodine-131 in his thyroid. If he maintained a continuous activity of $40 \mathrm{pCi}$ throughout the year, Table 2 shows that his thyroid would receive $11 \mathrm{mrad} / \mathrm{yr}$. However, if he had received a single thyroid burden of $40 \mathrm{pCi}$ of iodine-131 just before the thyroid measurement was made, then the dose to his thyroid would be $0.3 \mathrm{mrad}$. If this represented his only uptake of iodine-131 throughout the year, then his thyroid would receive 0.3 $\mathrm{mrad} / \mathrm{yr}$. If he were being measured quarterly, then the $40 \mathrm{pCi}$ could represent the residual from a single thyroid burden of $165,000 \mathrm{pCi}$ received just after his last quarterly measurement. This activity would have delivered $1,300 \mathrm{mrad}$ to his thyroid during the quarter of a year between measurements, or an annual dose rate of $5,200 \mathrm{mrad} / \mathrm{yr}$ as shown in Table 2. Table 2 shows similar possible dose rates for the other three family members measured.

\section{CONCLUSION}

The objective of this project was to determine the fcasibility and sensitivity of in vivo monitoring of the thyroid for iodine-131 at or 
TABLE 2. Activities, and corresponding dose rates, of iodine-131 in the thyroids of residents of a dairy farm located near a nuclear-power plant

\begin{tabular}{|c|c|c|c|c|c|c|c|}
\hline \multirow[b]{2}{*}{ Person } & \multirow[b]{2}{*}{$\begin{array}{l}\text { Counting } \\
\text { efficiency } \dagger \\
(\%)\end{array}$} & \multirow{2}{*}{$\begin{array}{l}\text { Iodine-131 } \\
\text { activity } \\
\text { in the } \\
\text { thyroid* } \\
\text { (pCi) }\end{array}$} & \multirow{2}{*}{$\begin{array}{c}\text { Effective } \\
\text { energy } \\
\left(\frac{\mathrm{MeV}}{\text { dis }}\right)\end{array}$} & \multirow[b]{2}{*}{$\begin{array}{l}\text { Thyroid } \\
\text { mass } \dagger \\
\text { (g) }\end{array}$} & \multicolumn{3}{|c|}{$\begin{array}{l}\text { Thyroid dose rates corresponding to measured } \\
\text { iodine-131 activity in the thyroid from a: }\end{array}$} \\
\hline & & & & & $\begin{array}{c}\text { Continuous } \\
\text { burden } \ddagger \\
\text { (mrad/yr) }\end{array}$ & $\begin{array}{l}\text { Single annual } \\
\text { burden§ } \\
\text { (mrad/yr) }\end{array}$ & $\begin{array}{c}\text { Single quarterly } \\
\text { burdenil } \\
\text { (mrad/yr) }\end{array}$ \\
\hline Husband & 4.2 & $<40$ & 0.23 & 16 & $<11$ & $<0.3$ & $<5,300$ \\
\hline Wife & 4.2 & $<40$ & 0.23 & 16 & $<11$ & $<0.3$ & $<5,300$ \\
\hline Daughter, age 7 & 5.9 & $<39$ & 0.21 & 4 & $<38$ & $<1.2$ & $<18,900$ \\
\hline Daughter, age 8 & 5.9 & $<39$ & 0.21 & 4 & $<38$ & $<1.2$ & $<18,900$ \\
\hline
\end{tabular}

* Counting time for background and people was $33.3 \mathrm{~min}$. Background count rate was $41 \mathrm{cpm}$.

$\dagger$ Values interpolated from Fig. 4.

¥ Calculated from equation (1). Assumes each person maintained a countinous burden of iodine-131 at the measured level throughout the year.

$\S$ Calculated from equation (2). Assumes each person received a single burden of iodinc-131 at the mcasurcd lcvel one time during a year. The single burden is assumed to have been received just before the thyroid measurement was made.

\| Calculated from equation (2). Assumes each person received a single burden of iodine-131 four times during a year. The single burden is assumed to have been received just after each thyroid measurement was made four times during the year.

below the limit set in Appendix I-10 CFR 50. Under normal counting conditions, the mobile thyroid-monitoring system can detect about $35 \mathrm{pCi}$ in a thyroid. Table 1 shows that this activity is too high to satisfy the legal requirement for the child who receives iodine-131 continuously from a nuclear-power plant. However, the mobile thyroid-monitoring system is sensitive enough to satisfy all other legal requirements in the United States provided that measurements are made soon enough after a single exposure.

In vivo thyroid measurements provide data on real people as opposed to air, milk and efflucnt measurements which must be extrapolated to people. Thyroid doses are calculated with smaller uncertainty factors from in vivo measurements $(2.1-2.6)$ than from air (3.87.8 ), milk (3.5), or effluent (5.6-8.8) measurements.

The mobile thyroid-monitoring system can be easily and quickly moved to a desired location for in vivo measurements. If the system were used routinely, the cost for each person measured would be about $\$ 30$.
Acknowledgement-The authors wish to extend their gratitude to Dr. G. Hoyt Whipple for his critical review of this paper.

\section{REFERENCES}

1. Report of the ICRP Committee II On Permissible Dose for Internal Radiation, p. 193. Pergamon Press, Oxford (1959).

2. Radiological Health Handbook, p. 213. U.S. Department of Health, Education Welfare, Washington, D.C. (1970).

3. Proposed Rule Making Action, Vol. 2, p. F-31. U.S. Nuclear Regulatory Commission, WASH1258, Washington, D.C. (1973).

4. Homann S., Plato P. and Jacobson A. P. Mobile thyroid monitoring system, final report. Consumers Power Company, Jackson, MI (1975).

5. Cunningham D. J. Cunningham's Textbook of Anatomy, 10th Edn, p. 537. Oxford University Press, London (1964).

6. Palmer H. E. et al. Standard methods of determining iodine-131 in human thyroids. Draft report, American Public Health Association (undated).

7. Mochizuki Y., Mowafy R. and Pasternack B. Hith Phys. 9, 1299 (1963). 